\title{
Bile reflux index after therapeutic biliary procedures
} Sedef Kuran*1, Erkan Parlak1, Gulden Aydog², Sabite Kacar¹, Nurgul Sasmaz', Ali Ozden ${ }^{3}$ and Burhan Sahin ${ }^{1}$

\author{
Address: ${ }^{1}$ Gastroenterology Department, Turkiye Yuksek Ihtisas Hospital, Ankara, Turkey, ${ }^{2}$ Pathology Department, Turkiye Yuksek Ihtisas \\ Hospital, Ankara, Turkey and ${ }^{3}$ Gastroenterology Department, Ankara University Faculty of Medicine, Ankara, Turkey \\ Email: Sedef Kuran* - sedefozdal@hotmail.com; Erkan Parlak - drerkanparlak@yahoo.com.tr; Gulden Aydog - Gulden476@hotmail.com; \\ Sabite Kacar - sabkacar@yahoo.com; Nurgul Sasmaz - sasmaznur@yahoo.com; Ali Ozden - ankaragastro@yahoo.com; \\ Burhan Sahin - drburhansahin@yahoo.com \\ * Corresponding author
}

Published: II February 2008

BMC Gastroenterology 2008, 8:4 doi:10.1 186/147/-230X-8-4

This article is available from: http://www.biomedcentral.com/I47I-230X/8/4

This is an Open Access article distributed under the terms of the Creative Commons Attribution License (http://creativecommons.org/licenses/by/2.0), which permits unrestricted use, distribution, and reproduction in any medium, provided the original work is properly cited.

\begin{abstract}
Background: Therapeutic biliary procedures disrupt the function of the sphincter of Oddi. Patients are potential "bile refluxers". The aim of this study was to assess how these procedures affect the histology-based bile reflux index (BRI), which can be used to reflect duodenogastric reflux (DGR).

Methods: Gastric antrum and corpus biopsies were collected from 131 subjects (56 men, 75 women; mean age, $55.9 \pm 15.6$ years). Group I (Biliary group-BG; $n=66$ ) had undergone endoscopic sphincterotomy, endoscopic stenting, or choledochoduodenostomy for benign pathology; Group $2(n=20)$ had undergone cholecystectomy alone; and Group $3(n=6)$ Billroth II gastroenterostomy. Group 4 (no cholecystectomy; $\mathrm{n}=39$ ) had upper endoscopy with normal findings and served as controls. BRI > I 4 indicated DGR (BRI [+]). To eliminate confounding effects of Helicobacter pylori $(H p)$ infection, comparisons were made according to $H p$ colonization.
\end{abstract}

Results: Fifty-nine subjects (45\%) were $\mathrm{Hp}(+)$. The frequencies of BRI (+) status in antrum and corpus specimens from $H p(-)$ BG patients were $74.3 \%$ and $71.4 \%$, respectively $(85.7 \%$ for both antrum and corpus for choledochoduodenostomy). Corresponding results were $60 \%$ and $60 \%$ for Group 2, $100 \%$ (only corpus) for Group 3, and $57.1 \%$ and $38.1 \%$ for controls (BG, Group 2, and Group 3 vs controls $-p>0.05$ antrum, $p<0.05$ corpus). Fifty-four BG patients had previously undergone cholecystectomy. Excluding those, the rates of BRI (+) in $\mathrm{HP} \mathrm{(-)} \mathrm{BG} \mathrm{patients} \mathrm{were} 75 \%$ antrum and $62.5 \%$ corpus ( $>0.05$ for both vs. Group 2 ).

Conclusion: Patients who had undergone biliary procedures showed similar bile-related histological changes in both corpus and antrum biopsies, but the changes seen in controls were more prominent in the antrum than corpus. Therapeutic biliary procedures increase the rate of BRI (+) especially in the case of choledochoduodenostomy. Therapeutic biliary procedures without cholecystectomy also increase the rate of $\mathrm{BRI}(+)$ similar to that observed in patients with cholecystectomy. 


\section{Background}

Duodenogastric reflux (DGR) is a poorly understood gastrointestinal process that is defined as reflux of duodenal contents into the stomach. It is very common for this condition to develop in adults who have undergone gastric surgery, pyloroplasty or cholecystectomy $[1,2]$. Duodenogastroesophageal reflux (DGER) is the disorder in which material from the duodenum passes into the stomach and the esophagus. Many recent studies have focused on the effects of DGR and DGER. Bile and duodenal contents have chronic noxious effects in both the stomach and the esophagus. Long-term exposure can cause dysplasia, intestinal metaplasia, ulcers and malignancy in the stomach, and Barrett's esophagus and various forms of esophageal malignancy [3].

The underlying mechanisms and motor events involved in DGR are not clear [3,4]. Researchers have looked at the anatomical impacts of pyloroplasty and Billroth II gastroenterostomy, gastric and duodenal motor function, and interactions among these processes. Motor coordination of the stomach, pylorus and duodenum, concentration of duodenal contents, and food intake have been identified as important factors in the development of DGR [4].

It is not clear whether functional and anatomic integrity of the sphincter of Oddi plays a role in DGR. Many patients who need therapeutic biliary procedures undergo endoscopic sphincterotomy, stent insertion, or choledochoduodenostomy and then continue life with a dysfunctional sphincter of Oddi. Such biliary procedures disrupt the control of bile flow into the duodenum, making these patients potential "refluxers". Currently, biliary reflux is usually measured with a fiberoptic spectrophotometer (Bilitec ${ }^{\varpi}$ ). However, Sobala et al. [5] developed a histologic index that identifies DGR based on several findings: edema in the lamina propria, intestinal metaplasia (IM), chronic inflammation, and gastric Helicobacter pylori $(\mathrm{Hp})$ infection. In this system, a histological bile reflux index (BRI) value above 14 indicates the presence of DGR.

The aim of this study was to investigate how therapeutic biliary procedures, which disrupt the function of the sphincter of Oddi, affect the gastric histology according to BRI.

\section{Methods}

The subjects for this prospective study were the patients who presented to our endoscopic retrograde cholangiopancreatography (ERCP) and endoscopy unit for investigation/treatment of various benign pathologies between April 2003 and October 2003. The reasons for visiting the unit included cholangitis, need for stent exchange, common bile duct stones, and benign biliary stricture. Exclusion criteria were history of alcohol abuse or portal hypertension, current use of a non-steroidal anti-inflammatory drug or any anticoagulant or antiaggregant, and presence of acute pancreatitis. Each subject was assigned to 1 of 4 groups and tissue specimens were collected (details below). Group 1 patients (biliary group [BG]; $n=$ 66) had undergone at least one of the following procedures for treatment of benign pathology: endoscopic sphincterotomy (ES), endoscopic stenting, or choledochoduodenostomy. The other patients had undergone cholecystectomy only (Group 2; $n=20$ ) or Billroth II gastroenterostomy (Group 3; $n=6$ ). Group 4 patients (controls; $n=39$ ) had no history of cholecystectomy but had undergone upper endoscopy for dyspepsia or reflux-like symptoms and had normal findings. The BG was divided into 3 subgroups based on the type of biliary procedure performed: ES and stenting (BG1), ES alone (BG2), and choledochoduodenostomy (BG3). All subjects were histologically evaluated for $\mathrm{Hp}$ infection, and history or not of cholecystectomy was noted for each BG patient. All patients provided written informed consent for the procedures and those who agreed to enter the study were enrolled; the ethical approval for this study was obtained from the Gastroenterology Clinical Council

ECRP was performed using a TJF-240 duodenoscope (Olympus, Japan) and upper gastrointestinal endoscopy was performed with a QX10 esophagogastroduodenoscope (Olympus, Japan). During the procedure, 2 biopsies were obtained from the gastric antrum and 2 from the corpus. A pathologist (GA) who was blinded to the patients' clinical findings assessed each gastric tissue sample according to the above-mentioned BRI system devised by Sobala et al. [5]. In this system, an index is derived based on the presence/severity of certain histological parameters: edema (denoted as $\mathrm{E}$ in the formula below) in the lamina propria, intestinal metaplasia (IM), chronic inflammation (CI in the formula below), and $\mathrm{Hp}$ colonization in the stomach. For every specimen, the pathologist assigned a grade from 0 to 3 (representing absent, mild, moderate, or marked, respectively) for each histological parameter. An index value was then calculated using a formula derived from stepwise logistic regression analysis:

$$
B R I=(7 \times E)+(3 \times I M)+(4 \times C I)-(6 \times H p) .
$$

According to Sobala and colleagues, a BRI above 14 indicates DGR (defined as bile acid level $>1 \mathrm{mmol} / \mathrm{L}$ [the upper limit of physiological reflux]) with $70 \%$ sensitivity and $85 \%$ specificity.

For analysis, any antrum or corpus specimen with BRI above 14 was identified as BRI (+). For each patient, the average BRIs for the 2 antrum specimens and for the 2 corpus specimens were calculated. The frequencies of antrum BRI $(+)$ and corpus BRI $(+)$ were then calculated for each 
patient group and for each BG subgroup. To eliminate the confounding effects of $\mathrm{Hp}$ infection on gastric mucosa, comparisons were made according to $H p$ colonization status. Analysis was also done to test for factors that can affect BRI (+) status, such as patient age and the interval from therapeutic procedure (ES, cholecystectomy, others) to biopsy collection. Group rates of cholecystectomy, IM, and $H p$ colonization were also separately evaluated in relation to age.

Statistical analysis was done using the Statistical Package for Social Sciences (SPSS for Windows, v. 11.0.0). Chisquare was used to compare the group frequencies of BRI (+) status. Regarding the other factors listed above, the Student $t$ test was used to compare results for parametric variables and the Mann-Whitney $U$ test to compare results for nonparametric variables. Results were expressed as mean \pm standard deviation and $p$ values less than 0.05 were considered statistically significant.

\section{Results}

A total of 131 patients (56 men and 75 women; mean age $55.9 \pm 15.6$ years) were included in the study. Tables 1 lists demographic features and $H p$ colonization status for the patient groups and BG subgroups. Of the 131 patients, $59(45 \%)$ were $H p(+)$. There were no significant differences among Groups 1, 2, 3 and 4 with respect to sex distribution, age or $H p(+)$ status.

Table 2 shows the frequencies of BRI (+) status (for antrum and corpus specimens separately) in each patient group as a whole and in the proportion of each group that was $H p(-)$. The frequencies of BRI (+) status for the antrum and corpus biopsies from the BG group and the corresponding frequencies for the $H p(-)$ individuals from this group were all higher than the corresponding values in the control group; however, only the differences between the corresponding corpus values were significant. The patients who had undergone Billroth II procedures (Group 3) had the highest BRI (+) frequencies (100\% BRI [+] in Group 3 as a whole and same for the Hp [-] patients; all 6 in this group were $H p[-])$. However, analysis excluding this group revealed that the frequencies of BRI (+) sta- tus in the corpus specimens from all patients in the BG (48.5\%) and in Group 2 (cholecystectomy only; 35\%), and from the proportions of these groups that were Hp () (71.4\% and $60 \%$, respectively) were significantly higher than the corresponding rates in the control group $(23.1 \%$ for whole group, 38.1\% for $H p$ [-] portion) ( $p<0.05$ for all). The frequencies of BRI (+) status for the antrum and corpus specimens from the $H p(-)$ individuals in the BG were both higher than the corresponding values in Group 2 , but these differences were not statistically significant (71.4\% vs. 60\%, respectively, for corpus; $74.3 \%$ vs. $60 \%$, respectively, for antrum; $p>0.05$ for both).

Table 3 shows the frequencies of BRI (+) status in each BG subgroup as a whole and in the proportion of each subgroup that was $H p(-)$. The Hp (-) portion of the choledochoduodenostomy subgroup (BG3) had the highest frequencies of BRI (+) status (85.7\% for corpus, $85.7 \%$ for antrum). Most patients in the BG (54 of 66) had undergone cholecystectomy. When these individuals were excluded from the analysis, the frequencies of BRI (+) status in the antrum and corpus biopsies from $H p(-)$ patients in the BG were $75 \%$ and $62.5 \%$, respectively. These values were not significantly different from the corresponding results in the $H p(-)$ patients of Group $2(60 \%$ and $60 \%$, respectively) ( $p>0.05$ for both).

Differences between frequencies of antrum BRI (+) status and corpus BRI $(+)$ status in each group were also compared. In the $\mathrm{BG}$, these differences were not significant (45.5\% vs. 48.5\%, respectively, for BG as a whole; $74.3 \%$ vs. $71.4 \%$, respectively, for the $H p(-)$ portion; $p>0.05$ for both). In Group 2, the frequencies of antrum and corpus BRI (+) status were $60 \%$ and $35 \%$ for the group as a whole, and $60 \%$ and $60 \%$ for the $H p(-)$ portion. Neither of these differences was significant ( $p>0.05$ for both). In Group 4, the frequencies of antrum and corpus BRI (+) status were $41 \%$ and $23 \%$, respectively, for the entire group and $57.1 \%$ and $38.1 \%$, respectively, for the $H p(-)$ portion ( $p>0.05$ for both).

The mean intervals from initial procedure to time of biopsy in BG1 (ES+stenting), BG2 (ES alone), and BG3

Table I: Demographic characteristics and $H$. pylori colonization status in the 4 patient groups and Group I subgroups.

\begin{tabular}{lllll}
\hline & N & Age (y) (mean \pm SD) & Cholecystectomy & No. Hp(+) N (\%) \\
\hline Group I & 66 & $55.4 \pm 13.6$ & $54(81.8)$ & $31(47)$ \\
BGI (ES+stent) & 28 & $52.7 \pm 12.5$ & $23(82.1)$ & $13(46.4)$ \\
BG2 (ES only) & 23 & $55.2 \pm 15.3$ & $16(69.7)$ & $10(43.5)$ \\
BG3 (Choledochoduodenostomy) & 15 & $60 \pm 11.9$ & $15(100)$ & $8(53.3)$ \\
Group 2 Cholecystectomy & 20 & $64 \pm 11.8$ & $20(100)$ & $10 / 20(50)$ \\
Group 3 Billroth II & 6 & $62.8 \pm 13.6$ & $2(33.3)$ & $0(0)$ \\
Group 4 Controls & 39 & $51.4 \pm 19.3$ & $0(0)$ & $18(46.2)$ \\
\hline
\end{tabular}

BG: Biliary group. ES: Endoscopic sphincterotomy. 
Table 2: Frequencies of BRI (+) status for antrum (A) and corpus (C) biopsies in the 4 patient groups, with results listed for all patients in each group and for the proportion that was $H p(-)$.

\begin{tabular}{lllll}
\hline & $\begin{array}{l}\text { BRI(+) A biopsies in } \\
\text { total group (\%) }\end{array}$ & $\begin{array}{l}\text { BRI(+) A biopsies in } \\
H p(-)(\%)\end{array}$ & $\begin{array}{l}\text { BRI(+) C biopsies in } \\
\text { total group (\%) }\end{array}$ & $\begin{array}{l}\text { BRI(+) C biopsies in } \\
\text { Hp(-) (\%) }\end{array}$ \\
\hline $\begin{array}{llll}\text { Group I (Biliary group) } \\
\text { Group 2 Cholecystectomy }\end{array}$ & $30 / 66(45.5)$ & $26 / 35(74.3)$ & $32 / 66(48.5)$ & $25 / 35(71.4)$ \\
Group 3 Billroth II & $12 / 20(60)$ & $6 / 10(60)$ & $7 / 20(35)$ & $6 / 10(60)$ \\
Group 4 Controls & - & - & $6 / 6(100)$ & $6 / 6(100)$ \\
P & $16 / 39(4 I)$ & $12 / 21(57.1)$ & $9 / 39(23.1)$ & $8 / 21(38.1)$ \\
\hline
\end{tabular}

BRI: Bile reflux index.

(choledochoduodenostomy) were $20.8 \pm 21.2$ months (range, 3-85 months; median, 13 months), $23.9 \pm 35.1$ months (range, 0.2-144 months; median, 11 months), and $61.3 \pm 77.8$ months (range, $2-300$ months; median, 41 months), respectively. In Group 2, the interval from cholecystectomy to biopsy was $85.3 \pm 112.5$ months (range, 1.2-384 months; median, 60 months). Analysis of the BG subgroups and Group 2 revealed no relationship between BRI (+) status in the specimens (antrum and corpus samples analyzed separately) and interval from procedure to biopsy ( $p>0.05$ for both antrum and corpus samples; Mann-Whitney U test).

The mean ages of the 131 subjects were compared according to BRI (+) and BRI (-) status in the antrum and corpus, and were determined as $58.9 \pm 15.4$ years $v$ s $52.6 \pm 15.5$ years for antrum $(\mathrm{p}=0.023)$ and $60.3 \pm 14.1$ years $v s 52.8$ \pm 16.1 years for corpus $(\mathrm{p}=0.007)$, respectively. In both categories of results, the BRI (+) status group had a significantly higher mean age.

Other factors linked with BRI (+) status were not found to change with age. When the mean ages of the 131 patients were determined in groups divided according to presence of IM (in antrum and corpus specimens separately [62.6 \pm 12.8 years $v s 52.7 \pm 16.1$ years; $61.6 \pm 13.3$ years $v s 54.6 \pm$ 15.9 years $]), H p$ colonization $(55.2 \pm 14.8$ years vs $56.5 \pm$ 16.4 years $)$, and history of cholecystectomy (57.3 \pm 13.7 years vs $53.9 \pm 18.1$ years $)$, no significant differences were determined. Analysis revealed that the patients with IM (+) antrum and corpus specimens were older than those with IM (-) antrum and corpus specimens, but the differences were not significant.

\section{Discussion}

Healthy individuals have anatomical and functional barriers that restrict increased intestinal reflux. The pylorus and the physiologically correct angle between the duodenum and the bulbus are the main anatomical factors. Antroduodenal motility, pyloric motility, and coordination of these activities are the main functional factors. The exact mechanisms of DGR are not known. This type of reflux is a physiological phenomenon that occurs postprandially and during sleep [6-9], but in some situations it becomes pathologic. This can occur, for example, after gastric surgery $[10,11]$ or cholecystectomy [12-15]. The healthy gastrointestinal tract has numerous mechanisms that defend against secretions, which are normally found in the lumen. However, proximal reflux of duodenal juice can damage unprotected mucosa [16]. Research has revealed much evidence that duodenal juice has noxious effects when it occurs in abnormal sites or accumulates in massive amounts [17-23]. As noted, therapeutic biliary procedures impair the function of the sphincter of Oddi, leading to uncontrolled flow of bile into the duodenum. These patients are prone to DGR. Only a few studies have evaluated the effects of therapeutic biliary procedures on DGR and the results are conflicting. Fountos et al. [24] investigated using scintigraphy and found that DGR is common after biliary surgery (cholecystectomy or cholecystectomy-choledochoduodenostomy) and procedures such as ES. They did not evaluate the Hp status of their

Table 3: Frequencies of BRI (+) status for antrum (A) and corpus (C) biopsies in the 3 study group (BG) subdivisions, with results listed for all patients in each subdivision and for the proportion that was $H p(-)$.

\begin{tabular}{|c|c|c|c|c|}
\hline & $\begin{array}{l}\text { BRI(+) A biopsies in } \\
\text { total group (\%) }\end{array}$ & $\begin{array}{l}\text { BRI(+) A biopsies in } \\
H P(-)(\%)\end{array}$ & $\begin{array}{l}\text { BRI(+) C biopsies in } \\
\text { total group (\%) }\end{array}$ & $\begin{array}{l}\text { BRI(+) C biopsies in } \\
H_{p(-)}(\%)\end{array}$ \\
\hline BGI ES+stent & $10 / 28(35.7)$ & $10 / 15(66.7)$ & $14 / 28(50)$ & $12 / 15(80)$ \\
\hline BG2 ES only & $\mathrm{I} 1 / 23(47.8)$ & $10 / 13(76.9)$ & $9 / 23(39.1)$ & $7 / 13(53.8)$ \\
\hline $\begin{array}{l}\text { BG3 } \\
\text { Choledochoduodenostomy }\end{array}$ & $9 / 15(60)$ & $6 / 7(85.7)$ & $9 / 15(60)$ & 6/7 (85.7) \\
\hline$p$ & $>0.05$ & $>0.05$ & $>0.05$ & $>0.05$ \\
\hline
\end{tabular}

BRI: Bile reflux index. BG: Biliary group. ES: Endoscopic sphincterotomy. 
patients. Tritapepe et al. [25] also investigated with scintigraphy and observed that choledochoduodenostomy did not increase DGR, whereas transduodenal sphincteroplasty did. Di Vita and colleagues [26] used scintigraphy to assess DGR in 23 patients (sphincterotomy performed in 16; choledochoduodenostomy in 7). They detected DGR in only 1 patient who had undergone sphincterotomy, but in almost all those who had undergone choledochoduodenostomy. In all these studies, scintigraphy was used to assess DGR and the impact of $H p$ infection was not evaluated. In our research, we used histological BRI to assess DGR. Our data indicate that therapeutic biliary procedures increase the frequency of BRI (+) status especially in choledochoduodenostomy.

It is difficult to diagnose DGR. Reports note conflicting results with respect to histopathologic changes in the gastric mucosa of these patients. Stein and colleagues [27] investigated the diagnostic value of gastric histology relative to degree of DGR and found a poor correlation. In contrast, Dixon et al. [17] used the histological BRI and detected a strong correlation between this index and gastric bile acid levels. Dixon and other co-workers (Sobala et al. [5]) had introduced their BRI system in a previous study, detailing the derivation of this index by stepwise logistic regression analysis of histological grades of various factors (edema, IM, chronic inflammation, Hp colonization). The later work by Dixon et al. [17] revealed that patients with Barrett's esophagus exhibit more evidence of bile-related gastritis than those with gastroesophageal reflux disease or non-ulcer dyspepsia. In an even more recent study, Dixon et al. [18] found that IM at the cardia was associated with histological evidence of bile reflux into the stomach. The Bilitec ${ }^{\circledR}$ device is the best method for monitoring bilirubin levels in the esophagus; however, interpretation of gastric bilirubin is more complex and Bilitec ${ }^{\circledR}$ is not as accurate in this setting [28-30]. Also, the value of measuring bilirubin is that high bilirubin levels indicate possible histologic changes in affected mucosa. The BRI is derived from observed changes in tissue histology and is, thus, an important tool that can reflect mucosal changes caused by bilirubin.

In our study, the frequencies of BRI (+) status in antrum and corpus biopsies from BG patients were similar to the corresponding rates in Group 2 (cholecystectomy only). Most of the BG patients (54 of 66) had undergone cholecystectomy. The BG subgroups who had undergone ES or stenting in addition to cholecystectomy had somewhat higher frequencies of BRI (+) status than Group 2 (cholecystectomy only), but these differences were not significant. Only the choledochoduodenostomy subgroup (BG3) had significantly higher frequencies of BRI (+) in both corpus and antrum biopsies when compared to Group 2. After choledochoduodenostomy, the opening of the common bile duct is located more proximal to the bulbus than its original site, and the angle at which it opens into the duodenum is changed. This anatomical alteration can lead to increased frequency of BRI (+) status. In Group 1 (BG), 54 patients had undergone cholecystectomy in addition to other therapeutic biliary procedures and the other 12 had undergone the therapeutic procedure(s) alone (no cholecystectomy) (Table 1). Within the latter group of 12 , the frequency of BRI (+) status in the individuals who were $H p(-)$ was similar to that observed in the Hp (-) portion of Group 2. These results suggest that performing therapeutic biliary procedures in patients who have already undergone cholecystectomy increases the likelihood of BRI (+) status, but therapeutic biliary procedures alone also increased the BRI (+) status as much as observed in patients who had cholecystectomy. Thus, therapeutic biliary procedures are a risk factor for increased frequency of BRI (+) status.

We also looked at relationships between various parameters in this study. The analysis indicated that, for patients who undergo ES, endoscopic stenting, choledochoduodenostomy or cholecystectomy, there is no relationship between the time at which the procedure is performed and BRI (+) status. In contrast, our results for age identified this as an important factor in the histological BRI system. The patients with BRI (+) status were significantly older than those who were BRI (-). A few previous studies have tested links between age and DGR. Bollschweiler et al. [31] evaluated bile reflux into the stomach and esophagus in a population of volunteers older than 40 years. They found no significant difference in reflux into the stomach when patients were grouped according to age (younger [median age 25 years] vs. older [median age 51 years]). Byrne and co-workers [32] also observed no link between age and DGR. In both of these studies, the Bilitec ${ }^{\circledR}$ method was used to measure levels of DGR. In contrast, our findings using the histological BRI system indicated that BRI $(+)$ status is more common in older than in younger individuals.

Our findings related to age made it essential to evaluate factors that can change with age, such as $H p$ colonization status, history of cholecystectomy, and presence of IM. We observed no significant differences in mean age when our 131 subjects were divided according to $H p$ colonization status $(H p[+] v s . H p[-])$ or according to history of cholecystectomy. When patients were categorized according to presence of IM in antrum and corpus specimens (separately), there were no significant differences between the mean ages of the groups with and without IM in both the antrum and the corpus. 


\section{Conclusion}

In conclusion, DGR is an important gastroenterological process that needs to be more fully understood. The goal of this study was to evaluate how various therapeutic biliary procedures affect the histology of the stomach. Our results indicate that therapeutic biliary procedures, especially choledochoduodenostomy, can be a risk factor for increased DGR. We also observed that, compared to controls, patients who had undergone biliary procedures showed similar bile-related histological changes in the corpus and the antrum. One would normally expect to find a higher level of bile in the antrum than in the corpus. Interestingly, in the groups/subgroups in our study that were at higher risk for increased DGR (i.e., patients with history of cholecystectomy, or those who had undergone cholecystectomy plus therapeutic biliary procedures), the frequency of increased DGR in the corpus was similar to that in the antrum. This suggests that bile reflux causes more marked histologic disturbances in the proximal stomach than in more distal areas. Our results also suggest that older patients and those who are $H p(-)$ are at higher risk for developing increased DGR.

\section{Competing interests}

The author(s) declare that they have no competing interests.

\section{Authors' contributions}

All authors read and approved the final manuscript.

S K made substantial contributions to conception and design of the study, and acquisition, analysis and interpretation of data, and was also involved in drafting the manuscript.

E P made substantial contributions to conception and design of the study, acquisition of data, and revision of the manuscript.

G A conducted pathological reporting and contributed to conception and design.

S K made substantial contributions to conception and design, was involved in drafting the manuscript, and provided critical revision of scientific content.

N S was involved in providing critical revision of scientific content.

A O was involved in providing critical revision of scientific content.

B S was involved in providing critical revision of scientific content, and gave final approval of the version to be published.

\section{References}

I. Malagelada JR, Phillips SP, Shorter RG, Higgins JA, Magrina C, van Heerden JA, Adson MA: Postoperative reflux gastritis: pathophysiology and long term outcome after Roux-en-Y diversion. Ann Int Med 1985, 103:173-183.

2. Cooperman AM: Postoperative alkaline reflux gastritis. Surg Clin North Am 1976, 56(6): I 445-59.

3. Stein HJ, Kauer WKH, Feussner H, Siewert JR: Bile acids as components of the duodenogastric refluxate: detection, relationship to bilirubin, mechanism of injury and clinical relevance. Hepatogastroenterology 1999, 46:66-73.

4. Koek GH, Vos R, Sifrim D, Cuomo R, Janssens J, Tack J: Mechanisms underlying duodeno-gastric reflux in man. Neurogastroenterol Motil 2005, I 7:191-199.

5. Sobala GM, O'Connor HJ, Dewar EP, King RF, Axon AT, Dixon MF: Bile reflux and intestinal metaplasia in gastric mucosa. J Clin Pathol 1993, 46:235-240.

6. Mackie C, Hulks G, Cuschieri A: Enterogastric reflux and gastric clearance of refluxate in normal subjects and in patients with or without bile vomiting following peptic ulcer surgery. Ann Surg 1986, 204:537-542.

7. King PM, Pryde A, Heading RC: Transpyloric fluid movement and antroduodenal motility in patients with gastroesophageal reflux. Gut 1987, 28:545-548.

8. Schindlbeck NE, Heinrich C, Stellaard F, Paumgartner G, Müller-Lissner SA: Healthy controls have as much bile reflux as gastric ulcer patients. Gut 1987, 28: 1577-83.

9. Fiorucci S, Distrutti E, Di Matteo F, Brunori P, Santucci L, Mallozzi E, Bigazzi U, Morelli A: Circadian variations in gastric acid and pepsin secretion and intragastric bile acid in patients with reflux esophagitis and in healthy controls. Am J Gastroenterol 1995, 90:270-276.

10. Offerhaus GJ, Rieu PN, Jansen JB, Joosten HJ, Lamers CB: Prospective comparative study of the influence of postoperative bile reflux on gastric mucosal histology and Campylobacter pylori infection. Gut 1989, 30:1552-1557.

II. Ritchie W: Alkaline reflux gastritis: a critical reappraisal. Gut 1984, 25:975-987.

12. Muller-Lissner SA, Schindlbeck NE, Heinrich C: Bile salt reflux after cholecystectomy. Scand J Gastroenterol Suppl 1987, 139:20-24.

13. Brown TH, Walton G, Cheadle WG, Larson GM: The alkaline shift in gastric pH after cholecystectomy. Am J Surg 1989, I 57:58-65.

14. Brough WA, Taylor TV, Torrance HB: The surgical factors influencing duodenogastric reflux. Br J Surg 1984, 71:770-773.

15. Kalima T, Sjoberg J: Bile reflux after cholecystectomy. Scand J Gastroenterol Suppl 1981, 67:153-156.

16. Byrne JP, Attwood SEA: Duodenogastric reflux and cancer. Hepatogastroenterology 1999, 46:74-85.

17. Dixon MF, Neville PM, Mapstone NP, Moayyedi P, Axon AT: Bile reflux gastritis and Barrett's oesophagus: further evidence of a role for duodenogastro-oesophageal reflux? Gut 200I, 49:359-363.

18. Dixon MF, Mapstone NP, Neville PM, Moayyedi P, Axon AT: Bile reflux gastritis and intestinal metaplasia at the cardia. Gut 2002, 5 I:35 I-355.

19. Mason RC: Duodenogastric reflux in rat gastric carcinoma. $\mathrm{Br}$ J Surg 1986, 73:80I-803.

20. Miwa K, Hattori T, Miyazaki I: Duodenogastric reflux and foregut carcinogenesis. Cancer 1995, 75:|426-|432.

21. Miwa K, Segawa M, Takano Y, Matsumoto H, Sahara H, Yagi M, Miyazaki I, Hattori T: Introduction of oesophageal and forestomach carcinomas in rats by reflux of duodenal contents. $\mathrm{Br} J$ Cancer 1994, 70:185-189.

22. Champion G, Richter JE, Vaezi MF, Singh S, Alexander R: Duodenogastroesophageal reflux: relationship to $\mathrm{pH}$ and importance in Barrett's esophagus. Gastroenterol 1994, I 08(3):747-754.

23. Vaezi MF, Richter JE: Synergism of acid and duodenogastroesophageal reflux in complicated Barrett's esophagus. Surgery 1995, I I 7:699-704.

24. Fountos A, Chrysos E, Tsiaoussis J, Karkavitsas N, Zoras OJ, Katsamouris A, Xynos E: Duodenogastric reflux after biliary surgery: scintigraphic quantification and improvement with erythromycin. ANZJ Surg 2003, 73:400-3. 
25. Tritapepe R, Piro D, Damilano I: Long-term effects in bilio-digestive shunts. Ital J Gastroenterol 1993, 25:425-428.

26. Di Vita G, Siragusa G, Asaro M, Costa R, Salerno V, Di Pace G: BrIDA in the evaluation of papillo-sphincterotomy and choledochoduodenostomy. Minerva Chir 1991, 46: I75-I78.

27. Stein HJ, Smyrk TC, Demeester TR, Rouse J, Hinder RA: Clinical value of endoscopy and the histology in the diagnosis of duodenogastric reflux disease. Surgery 1992, I | 2:796-804.

28. Tibbling Grahn L, Blackadder L, Kullman E: Gastric bile monitoring: an in vivo and in vitro study of Bilitec reliability. Scand J Gastroenterol 2002, 37:1334-1337.

29. Bechi $P$, Cianchi F: Technical aspects and clinical indications of 24-hour intragastric bile monitoring. Hepatogastoenterology 1999, 46:54-59.

30. Fuchs K-H, Fein M, Maroske J, Heimbucher J, Freys SM: The role of 24-hr gastric pH-monitoring in the interpretation of 24-hr gastric bile monitoring for duodenogastric reflux. Hepatogastroenterology 1999, 46:60-65.

31. Bollschweiler E, Wolfgarten E, Putz B, Gutschow C, Holscher AH: Bile reflux in to the stomach and esophagus for volunteers older than 40 years. Digestion 2005, $71: 65-71$.

32. Byrne JP, Romagnoli R, Bechi P, Attwood SE, Fuchs KH, Collard JM: Duodenogastric reflux of bile in health: the normal range. Physiol Meas 1999, 20:149-158.

\section{Pre-publication history}

The pre-publication history for this paper can be accessed here:

http://www.biomedcentral.com/1471-230X/8/4/prepub

Publish with Biomed Central and every scientist can read your work free of charge

"BioMed Central will be the most significant development for disseminating the results of biomedical research in our lifetime. "

Sir Paul Nurse, Cancer Research UK

Your research papers will be:

- available free of charge to the entire biomedical community

- peer reviewed and published immediately upon acceptance

- cited in PubMed and archived on PubMed Central

- yours - you keep the copyright

Submit your manuscript here:

http://www.biomedcentral.com/info/publishing_adv.asp 